\title{
Book Note
}

\section{Complementing Parents: A Short Review of The Critical Years by Doris Durrell}

\author{
Stephen Ledoux \\ State University of New York, Canton
}

Some years ago, B. F. Skinner (1981) presented a paper titled "We Happy Few but Why so Few?" His title summarizes the sentiments of many professional behavior analysts who have long recognized the benefit our culture would gain if its members applied some basic behavioral principles and concepts to ordinary daily interactions. Other disciplines are not as ignored by the public as behavior analysis seems to be. Skinner comprehensively analyzed some broad cultural reasons for this in Beyond Freedom and Dignity (1971). These considerations aside, another reason behavior analysis is ignored may simply be that few books on behavioral psychology are available for the general population, as a scan of local bookstore shelves reveals (see also Morris, 1985).

Some behavioral books, of course, have been widely read, among them Walden Two (Skinner, 1948). Other behavioral books for general audiences have also been written, but with varying degrees of success. Some books offer an overview of ordinary daily applications of the behavioral approach, such as Pryor's (1984) Don't Shoot the Dog. Other books have a general appeal to wider audiences, such as Skinner and Vaughan's (1983) Enjoy Old Age. Many other books, however, are

The Critical Years: A Guide for Dedicated Parents is available from New Harbinger Publications, Suite 305, 2200 Adeline Street, Oakland, CA 94607 (207 pp., \$9.95, paperback). This note is an abridged version of a longer review (Ledoux, in press). For either version, send reprint requests to Dr. Stephen Ledoux, Department of Psychology, SUNY-Canton, Canton, NY 13617. The author thanks the editor and anonymous reviewers of The Behavior Analyst for their helpful comments on an early draft of this paper. more limited in scope and are often written chiefly to help the already distraught parent (Becker, 1971; Patterson, 1975, 1976). Writing for distraught parents, where the emphasis is on solving already developed problems, may have reduced the chance that these works would be picked up by the ordinary bookstore customer for simple informative reading or as gifts for friends. Finally, Skinner aside, behavioral psychology does not have the sorts of popular writers that other disciplines have-we have no Isaac Asimovs or Stephen Jay Goulds. A book that begins to break this mold, however, is Doris Durrell's (1984) The Critical Years: A Guide for Dedicated Parents.

The purpose of this brief review differs from the usual. The usual purpose is to show readers where and how a book fits into the present scheme of the discipline and to encourage readers to obtain and read it for their own edification. Trained behavior analysts, however, are already familiar with the information contained in The Critical Years. The book was not written for the professional but for the lay person. The purpose of this note is to inform behavior analysts about the book so that they may use it and recommend it to others, the latter of which may successfully promote improvements in our culture's child-rearing practices.

Before describing the book's content, a number of its outstanding characteristics deserve specific attention. Sometimes these characteristics are obvious; more often, they are found between the lines. First, the overall aim of the book is to improve our culture's child-rearing practices by teaching parents a planned approach (based on principles of behavior rather than on causes attributed to 
ages and stages) to the more significant aspects of child rearing, including language development and training, the effects and appropriate use of punishment, social skills training, intelligence, and creativity.

Second, the underlying theme of the book is primary prevention rather than crisis intervention, as seen in the emphasis on the early and easy solving of emerging behavior problems. The tactic is one of "Let's do it right the first time" to avoid later problems if possible. Not suprisingly, Durrell concentrates her efforts on the practices applicable from birth to three years of age, although she also gives much advice on how to continue after that. This theme, with the emphasis on the first three years, differs from most behavioral books on child rearing, such as those mentioned earlier. Those books usually deal with older children and can usually be characterized as cure-oriented. Problems have already developed, and those books suggest ways for solving them. The Critical Years is different, taking the view that such problems "might have been prevented altogether with the application of a few simple psychological principles" (Durrell, 1984, p. 11, italics in original). Durrell's goals are to make the principles obvious and their application routine for the daily life of the dedicated parent. In my opinion, the author achieves her goals remarkably well.

Third, and finally, the quality of Durrell's examples merits special recognition. They are drawn from actual situations that every parent probably experiences. Moreover, when stressing that parents should model desirable behaviors for their child (an important point in its own right), Durrell also practices what she preaches by providing familiar and helpful concrete models to follow. In these regards, Durrell also proceeds without gender bias. Son and daughter examples alternate, and do not reflect standard gender stereotypes.

As for the content of the book, it is divided into four parts. Part I, Basic Childbearing Facts, contains three chapters on (1) the first three years, (2) easy, slow to warm up, and difficult babies, and
(3) attachment, substitute care, and sleep behavior. Part II, Advanced Childrearing Techniques, contains four chapters on (4) promoting language development, (5) intelligence, (6) creativity, and (7) achievement motivation. Part III, Socialization, contains two chapters on (8) disobedience and temper tantrums, and (9) aggression, empathy, sharing, and cooperation. Part IV, Behavior Modification, contains four chapters on (10) increasing desirable behavior, (11) modeling behavior, (12) decreasing undesirable behavior, and (13) teaching, preventing, and eliminating fears. An index and bibliography are also included. (See Ledoux, in press, for a more complete description and discussion of the book's content).

Overall, The Critical Years, although not perfect, seems to be the most organized and readable presentation of scientifically sound information, advice, and examples concerning child rearing practices available at this time. Additional chapters, or perhaps even a separate volume, devoted to a discussion of methods for handling situations that arise in the next nine years of a child's life (ages 312), in the same amount and type of detail used to cover the first three years, would be welcome. Durrell's preventative approach similarly applied to these later years could improve the lives of many parents and children.

Until a separate book or additional chapters in The Critical Years appear, Christophersen's (1982) Little People (from Pro-Ed, 5341 Industrial Oaks Blvd, Austin, TX 78735) provides quite usable coverage of these years. Although shorter than The Critical Years, Little People nonetheless also admirably pursues the preventative approach. Indeed, rather than competing, the two books compliment each other. A comprehensive understanding and set of successful strategies will likely accrue to parents who use both books.

The prevention, rather than cure, orientation of The Critical Years serves another purpose in addition to those mentioned previously. It enhances the potential popularity of the book by re- 
moving the implications of guilt and insult that are often associated with books taking a cure approach. Some parents may hesitate to buy any of the excellent cureoriented books, when one is needed, partly out of fear of self-recrimination about having failed in some way. Parents may also be insulted if someone recommends or gives them such a book. Preventionoriented books, however, are easier to buy and to give as gifts because the approach does not imply that problems already exist. Hence, prevention-oriented books are more likely to reach larger audiences and have a greater impact in improving cultural practices. Such is the potential role that The Critical Years can serve regarding child-rearing practices.

\section{REFERENCES}

Becker, W. C. (1971). Parents are teachers. Champaign, IL: Research Press.
Christophersen, E. (1982). Little people. Austin, TX: Pro-Ed.

Durrell, D. E. (1984). The critical years: A guide for dedicated parents. Oakland, CA: New Harbinger Publications.

Ledoux, S. (in press). Expanding the happy few: A Review of The Critical Years by Dorris Durrell. Behavior Analysis and Social Action.

Morris, E. K. (1985). Public information, dissemination, and behavior analysis. The Behavior Analyst, 8, 95-110.

Patterson, G. R. (1975). Families. Champaign, IL: Research Press.

Patterson, G. R. (1976). Living with children. Champaign, IL: Research Press.

Pryor, K. (1984). Don't shoot the dog. New York: Simon and Schuster.

Skinner, B. F. (1948). Walden two. New York: Macmillan.

Skinner, B. F. (1971). Beyond freedom and dignity. New York: Knopf.

Skinner, B. F. (1981, May). We happy few but why so few? Paper presented at the meeting of the Association for Behavior Analysis, Milwaukee, WI.

Skinner, B. F., \& Vaughan, M. E. (1983). Enjoy old age. New York: W. W. Norton. 